\title{
Effect of esomeprazole on maternal serum soluble fms-like tyrosine kinase-1 and endoglin in patients with early-onset preeclampsia
}

\author{
Ahmed M. Abbas, ${ }^{1}$ Yousra M. Othman, ${ }^{1}$ Mohamad M. Abdallah, ${ }^{1}$ Noura H. Abd Ellah, ${ }^{2}$ \\ Hanan G. Abdel Azim, ${ }^{3}$ Ayman H. Shaamash ${ }^{1}$
}

Keywords: Preeclampsia, esomeprazole, proton pump inhibitors, endoglin

\begin{abstract}
Objective: This study evaluates the effect of esomeprazole on the maternal serum levels of soluble fms-like tyrosine kinase-1 (sFlt-1) and soluble endoglin (sEng) in patients with earlyonset preeclampsia.
\end{abstract}

Methods: A randomized, double-blind, placebocontrolled trial was carried out in a tertiary University hospital between March 2018, and September 2019 (Clinical Trials.Gov: NCT03213639). The study included women between 28 and 31+6 weeks gestational age who had been diagnosed as preeclampsia without severe features. They were randomly assigned in a 1:1 ratio into an esomeprazole group, which received esomeprazole $40 \mathrm{mg}$ orally once a day, and a placebo group, which received one placebo tablet daily. Blood samples were obtained to assess levels of serum sFlt-1and sEng using ELISA testing. The primary outcome was the difference between the mean serum level of sFlt-1 and sEng at the start of treatment and at the termination of pregnancy in both groups.

Results: Eighty-eight patients were randomly assigned into both groups (44 in each). No statistically significant difference was found in the levels of sFlt-1 between both groups at admission and termination of pregnancy. The number of days of treatment for the esomeprazole group was slightly longer than the placebo group $(11.4 \pm 9.4$ vs. $10.3 \pm 6.3$ days, $P=0.515)$. No statistically significant difference in the rate of maternal and fetal complications occurred between the two groups. No side effects from the study medications were reported.

Conclusions: Esomeprazole, at the dosage used in this study did not effectively lower the serum levels of sFlt-1 and sEng in patients with early-onset preeclampsia. Furthermore, it did not prolong the duration of pregnancy, nor did it decrease maternal or fetal complications.

${ }^{1}$ Department of Obstetrics \& Gynecology, Faculty of Medicine, Assiut University, Egypt. ${ }^{2}$ Department of Pharmaceutics, Faculty of

Please cite this paper as: Abbas AM, Othman YM, Abdallah MM, Ellah NHA, Azim HGA, Shaamash AH. Effect of esomeprazole on maternal serum soluble fms-like tyrosine kinase-1 and endoglin in patients with early-onset preeclampsia. Proc Obstet Gynecol. 2022;11(1):Article 2 [ 14 p.]. Available from: https://pubs.lib.uiowa.edu Free full text article.

Corresponding author: Ahmed M. Abbas, MD, Department of Obstetrics and Gynaecology, Assiut University, Women Health Hospital, Assiut, Egypt, 71511. Cellular: +20 10033851833, Tel: +20882414616, Fax: +20889202503. E-mail: $\underline{\text { bmr90@hotmail.com }}$

Financial Disclosure: The authors report no conflict of interest. The authors received no funding from an external source.

Copyright: (c) 2022 Abbas et al. This is an open-access article distributed under the terms of the Creative Commons Attribution License, which permits unrestricted use, distribution, and reproduction in any medium, provided the original author and source are credited. 
Pharmacy, Assiut University, Egypt.

${ }^{3}$ Department of Clinical Pathology, Faculty of Medicine, Assiut University, Egypt.

\section{Introduction}

Preeclampsia is a disorder of widespread vascular endothelial malfunction and vasospasm that occurs after 20 weeks' gestation and can present as late as 4-6 weeks postpartum. ${ }^{1}$ Among all cases of preeclampsia, only $10 \%$ occur in pregnancies of less than 34 weeks gestation. The global incidence of preeclampsia has been estimated to affect $5-14 \%$ of all pregnancies. In developing nations, the incidence of the disease is reported to be $4-18 \%{ }^{2,3}$ Globally, preeclampsia is responsible for more than 60,000 maternal deaths annually. ${ }^{4}$ Furthermore, while early delivery of patients with preeclampsia can reduce maternal mortality, it has adverse consequences for the babies delivered. Fetuses delivered at less than 33 weeks' gestation are at significant risk of severe disability, including cerebral palsy, stroke (intracerebral bleeding), retinopathy of prematurity, chronic lung disease and death. ${ }^{5}$

Although the etiology of preeclampsia is still unclear, its manifestations, including endothelial dysfunction, hypertension, proteinuria, and possible multisystem organ injury, are thought to be mediated by high concentrations of circulating antiangiogenic proteins such as soluble fms-like tyrosine kinase-1 (sFlt-1) and soluble endoglin (sEng) in the maternal blood stream. ${ }^{6}$ Despite considerable research, the only technique that can confidently mediate both the maternal and fetal adverse effects of preeclampsia is termination of the pregnancy, which poses a difficult clinical dilemma for early-onset preeclampsia. $^{5}$

Proton pump inhibitors (PPIs) have been commonly used in pregnancy to treat gastroesophageal reflux disorders and more serious gastrointestinal complications like Helicobacter pyloriinfection, peptic and duodenal ulcers and Zollinger-Ellison syndrome, ${ }^{7}$ and have been considered for treatment of preeclampsia. In a recent study by Onda et al., ${ }^{8}$ PPIs decreased sFlt-1 and sEng secretion from trophoblasts, placental explants from preeclamptic pregnancies, and endothelial cells. PPIs decreased endothelin-1 secretion and enhanced endothelial cell migration. Additionally, esomeprazole (one of PPIs) vasodilated maternal blood vessels from normal pregnancies and cases of preterm preeclampsia. In the same study, they found that esomeprazole decreased blood pressure in a transgenic mouse model, where human sFlt-1 was overexpressed in the placenta. They conclude that esomeprazole has therapeutic potential for preeclampsia and other diseases where endothelial dysfunction is involved. ${ }^{8}$ Esomeprazole was discovered to have highly potent effects in inducing Heme-oxygenase-1 (HO-1). In 2018, Cluver et al., ${ }^{10}$ the only previous randomized controlled trial (RTC) related to this research, found that esomeprazole induced $\mathrm{HO}-1$ by 11.5-fold in endothelial cells and 3.9-fold in purified primary trophoblast cells. These findings suggest that esomeprazole may potently induce the antioxidant enzyme $\mathrm{HO}-1$ in both primary human endothelial and placental cells. This makes it an exciting 
candidate for drug therapy for preeclampsia. ${ }^{9}$ Therefore, the current study aimed to evaluate the effect of esomeprazole on the serum level of sFlt-1 and sEng in patients with earlyonset preeclampsia.

\section{Patients and Methods}

The current study was a randomized, double-blind, placebo-controlled trial conducted in a tertiary University hospital between March 2018 and September 2019. The Institutional Ethical Review Board approved the study protocol. Written informed consent was obtained from all participants after discussion of the nature of the study.

\section{Eligible participants}

We invited all women who attended the hospital's emergency unit with symptoms or signs of preeclampsia to be enrolled in the study if they met our inclusion criteria. We included women aged 18-45 years, with a singleton pregnancy, gestational age between 28 and $31+6$ weeks, diagnosed with preeclampsia without severe features that could be managed conservatively according to ACOG guidelines, 2013.11 Participants were excluded if they had established fetal compromise that necessitated delivery, or if they demonstrated criteria for preeclampsia with severe features like severe hypertension, eclampsia, cerebrovascular stroke, renal impairment, left ventricular failure, pulmonary edema, disseminated intravascular coagulation (DIC), hemolysis, elevated liver enzymes, low platelets (HELLP syndrome), or if they were currently using PPI, or if the use of
PPI was contraindicated.

\section{$\underline{\text { Sample size }}$}

Sample size was calculated using Version 2.3.1. of the open Epi software program. A previous study reported that the mean value of the serum level of sFlt-1 in preeclampsia patients was 1764 pglml.9 We proposed that esomeprazole would decrease the serum level by at least $30 \%$ in treated women. We then used a standard deviation of $757 \mathrm{pg} / \mathrm{ml}$, a error $=0.05$ and $90 \%$ power applied to data from a total sample size of 88 women (44 in each group) to determine if there was, in fact, the anticipated decrease in serum level of sFlt-1 (Epi-info ${ }^{\mathrm{TM}}$, Centers for Disease Control and Prevention, USA).

\section{$\underline{\text { Recruitment }}$}

One of the study researchers (Y. M. O.) approached all included women and collected the baseline data. The resulting detailed history included age, residence, parity, gestational age, previous miscarriages, history of preeclampsia and body mass index (BMI) calculated for each participant.

\section{$\underline{\text { Randomization }}$}

We randomly assigned all participants in a 1:1 ratio into one of two groups:

- Esomeprazole group (Group A): women used Esomeprazole (Esmopex, Int. Drug Agency for Pharm. Ind., Egypt) in a dose of $40 \mathrm{mg}$, given orally once a day.

- Placebo group (Group B): women used an inert placebo 
tablet similar in appearance, color and consistency to the esomeprazole tablets used for the previous group. The placebo tablets were manufactured in the Department of Pharmaceuticals, Faculty of Pharmacy, Assiut University, Egypt.

A statistician, not otherwise involved in the study, prepared a computergenerated table of random numbers to use as patient identifiers and sealed allocation data in serially numbered envelopes. Each envelope contained a card noting the group identifier. Each envelope had a card stating the intervention inside either group (A) or (B). Allocation was unchanged after the closed envelopes had been opened.

Manufacture, packaging and labeling of placebo tablets for both groups $A$ and $B$ was performed by a single pharmacist (N.H.A.). As a result, neither the researchers nor the participants knew to which group women were assigned or the nature of the drug they were given. The study researcher opened the envelopes according to the order of attendance of women and used the box A or B according to the card. We asked the participants to keep empty medication packets for confirming the compliance of drug intake.

\section{Intervention}

All patients were clinically examined for vital signs, and for general and abdominal health. Blood pressure was measured using a mercury sphygmomanometer with patients in a supine position. Fetal assessment was done using an ultrasound diagnostic imaging machine (Medison X6, Seoul. South Korea) to measure fetal biometry, estimated fetal weight and amniotic fluid index. Maternal renal function, liver function, coagulation profile, serum uric acid, complete blood count and 24-hour urinary protein excretion were determined upon admission for each participant in order to exclude women with maternal health complications.

A trained nurse from the emergency ward collected the blood samples from the participants. Blood samples (three $\mathrm{ml}$ venous blood per sample) were obtained at the time of admission under complete aseptic conditions. Samples taken before the start of medication intake and within $24 \mathrm{~h}$ after termination of the pregnancy were used to assess levels of serum endoglin and sFIt-1 using an ELISA test PR4100 (BioRad) programming reader system for human soluble ENDOGLIN /CD105 ELISA KIT \{SinoGeneclon Biotech\}: catalog No.: SG-10466 and for human soluble FMSlike TYROSINE KINASE -1 ELISA KIT \{SinoGeneclon Biotech\}: catalog No.: SG-10522.

\section{Assay Procedures}

The principal behind the immunoassays used in this research are based on using a] antibody specific for each of the angiogenic markers under study in a process that compares actual blood samples to cloned samples provided by the manufacturer. We used this procedure to determine levels of both serum soluble endoglin and serum sFIt1 in blood samples from both esomeprazole and placebo groups of our study population following directions provided by the manufacturer, 
SinoGeneclon Biotech. Outcomes for the assays are determined by comparing the color of bound endoglin or sFlt-1, respectively, remaining on a pre-coated microplate.

\section{Follow up}

Original intake, evaluation, examination, and assignment to study groups took place in a hospital setting. However, follow up activities were conducted in an antenatal care clinic on an outpatient basis. Regular, weekly maternal follow up included blood pressure measurement and blood tests (complete blood count, renal function tests, and liver functions). Weekly fetal follow up included measurement of fetal growth rate and assessment of amniotic fluid using cardiotocography and ultrasound.

Delivery of the patient was done in the following conditions:

- Reaching mature gestational age ( $\geq 37$ weeks)

- Development of any of criteria indicating increased severity of preeclampsia

- Occurrence of a non-reassuring cardiotocograph or of intrauterine fetal death.

Patients were followed until delivery, and the occurrence of any maternal or fetal complications was reported. Any maternal admission to the intensive care unit (ICU) and the duration of said admissions were also recorded.

\section{Study outcomes}

The primary outcome was the difference between the mean serum level of sFlt-1 and sEng at the start of treatment and at the termination of pregnancy in both groups. Secondary outcomes included the duration of prolongation of pregnancy measured from the time of enrolment to the time of delivery, the rate of maternal and fetal complications in both groups and the occurrence of side effects of the medications.

\section{Statistical analysis}

Statistical analysis was performed using IBM SPSS Statistics version 20 (SPSS Inc., Chicago, IL, USA). Categorical data were presented as frequencies and percentages, while the Chi-square test was used for comparisons between groups. Continuous data were reported as mean \pm standard deviation andlor median and range (min-max) and tested for normality using the Shapiro-Wilkes test. Where continuous data were normally distributed, the Student's T-test was used to compare groups; where data were non-normally distributed, the Mann-Whitney test was used. For comparison between variables at the time of admission and after termination for each group, Wilcoxon signed-rank test was used. Kaplan-Mayer survival analysis and curve were performed to determine the mean time for each group to termination of pregnancy. In all statistical tests, $p$-value $<0.05$ was considered statistically significant.

\section{Results}

One hundred one women were assessed for eligibility for inclusion in 
the study. Nine women did not meet our inclusion criteria, and four women declined to participate in the study. In the end, 88 patients were enrolled in the study and randomly assigned to groups
(44 in each). All patients were followed until termination of pregnancy; in the esomeprazole group, three patients were lost to follow-up versus one patient in the placebo group. (Figure 1)

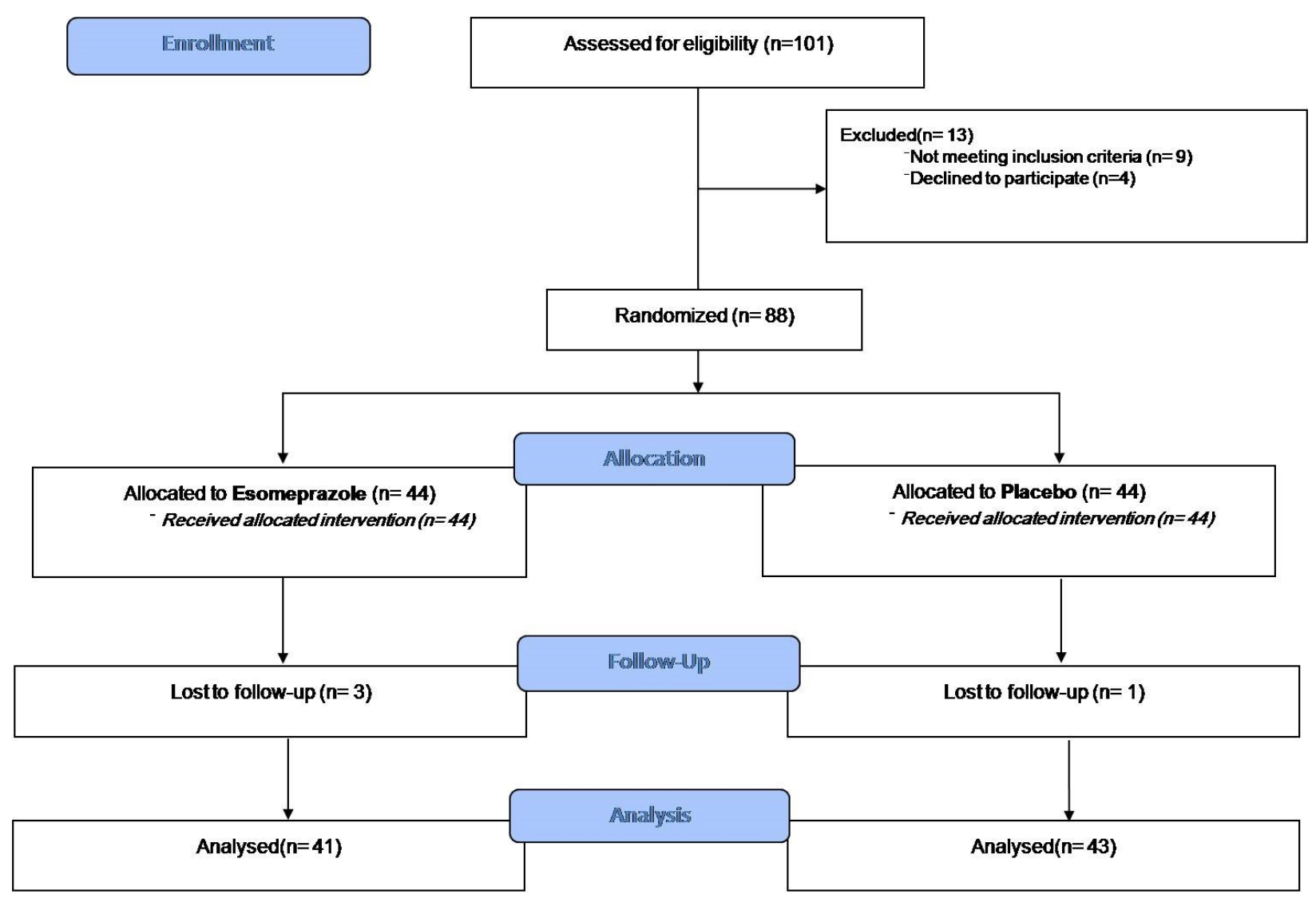

Figure 1. The study flowchart

Table 1 shows that both groups were demographics and clinical similar with regard to their baseline characteristics $(P>0.05)$. 
Table 1. The baseline demographic and clinical characteristics of the study groups

\begin{tabular}{|c|c|c|}
\hline Characteristics & $\begin{array}{l}\text { Esomeprazole group } \\
(n=41)\end{array}$ & $\begin{array}{c}\text { Placebo group } \\
(n=43)\end{array}$ \\
\hline Age (years) & $28.4 \pm 5.2$ & $28.7 \pm 5.7$ \\
\hline$B M I\left(K g / m^{2}\right)$ & $27.2 \pm 2.1$ & $27.9 \pm 2.0$ \\
\hline Primiparas $\#$ & $21(51.2 \%)$ & $18(41.8 \%)$ \\
\hline History of Preeclampsia & $10(24.4 \%)$ & $10(23.2 \%)$ \\
\hline Residence $^{\#}$ & & \\
\hline Urban & $4(9.8 \%)$ & $5(11.6 \%)$ \\
\hline Rural & $37(90.2 \%)$ & $38(88.4 \%)$ \\
\hline Gestational age (weeks) & $29.6 \pm 1.5$ & $30.1 \pm 1.1$ \\
\hline Systolic blood pressure $(\mathrm{mmHg})$ & $158.3 \pm 9.9$ & $157.2 \pm 7.4$ \\
\hline Diastolic blood pressure (mmHg) & $97.1 \pm 4.8$ & $97.5 \pm 4.6$ \\
\hline Estimated fetal weight (grams) & $1399.3 \pm 283.8$ & $1328.1 \pm 287.3$ \\
\hline
\end{tabular}

Table 2. Serum sFIt-1 level at admission and termination of pregnancy in the study groups in $\mathrm{pg} / \mathrm{ml}$

\begin{tabular}{|c|c|c|c|c|}
\hline & & $\begin{array}{c}\text { Esomeprazole group } \\
\qquad(n=41)\end{array}$ & $\begin{array}{l}\text { Placebo group } \\
\quad(n=43)\end{array}$ & P-value ${ }^{1}$ \\
\hline At admission & Mean \pm SD & $1218.56 \pm 119.76$ & $1199.34 \pm 226.76$ & 0.522 \\
\hline \multicolumn{2}{|c|}{30 weeks } & $n=16$ & $n=9$ & \\
\hline At termination & Mean \pm SD & $671.1 \pm 127.78$ & $710.4 \pm 225.06$ & 0.760 \\
\hline \multicolumn{2}{|c|}{$P$-value $e^{2}$} & $<0.001$ & $<0.001$ & \\
\hline \multicolumn{2}{|c|}{32 weeks } & $n=14$ & $n=24$ & \\
\hline At termination & Mean \pm SD & $677.92 \pm 153.86$ & $682.26 \pm 168.38$ & 0.961 \\
\hline \multicolumn{2}{|c|}{$P$-value $e^{2}$} & $<0.001$ & $<0.001$ & \\
\hline \multicolumn{2}{|c|}{34 weeks } & $n=11$ & $n=10$ & \\
\hline At termination & Mean \pm SD & $666.72 \pm 179.54$ & $650.52 \pm 236.26$ & 0.861 \\
\hline \multicolumn{2}{|c|}{$P$-value ${ }^{2}$} & $<0.001$ & $<0.001$ & \\
\hline
\end{tabular}

Data are presented as mean $\pm S D$.

$P$-value ${ }^{1}$ : Mann-Whitney test was used. P-value ${ }^{2}$ : Wilcoxon signed rank test was used. 
Table 2 shows no statistically significant difference in the levels of sFlt-1 between groups both at admission and termination of pregnancy. However, in both groups, the sFIt-1 level showed a significant decrease at the termination of pregnancy $(P<0.001)$. Similar results were observed regarding the levels of serum endoglin. (Table 3)

Table 3. Serum endoglin level at admission and termination of pregnancy in the study groups in $\mathrm{pg} / \mathrm{ml}$

\begin{tabular}{|c|c|c|c|c|}
\hline & & $\begin{array}{c}\text { Esomeprazole group } \\
(\mathrm{n}=\mathbf{4 1 )}\end{array}$ & $\begin{array}{l}\text { Placebo group } \\
\quad(n=43)\end{array}$ & P-value ${ }^{1}$ \\
\hline At admission & Mean \pm SD & $640.52 \pm 117.56$ & $610.32 \pm 188.38$ & 0.383 \\
\hline \multicolumn{2}{|c|}{30 weeks } & $n=16$ & $n=9$ & \\
\hline At termination & Mean \pm SD & $178.66 \pm 65.98$ & $164.58 \pm 54.74$ & 0.187 \\
\hline \multicolumn{2}{|c|}{$P$-value ${ }^{2}$} & $<0.001$ & $<0.001$ & \\
\hline \multicolumn{2}{|c|}{32 weeks } & $n=14$ & $n=24$ & \\
\hline At termination & Mean \pm SD & $152.18 \pm 56.12$ & $133.26 \pm 33.98$ & 0.241 \\
\hline \multicolumn{2}{|c|}{$P$-value $e^{2}$} & $<0.001$ & $<0.001$ & \\
\hline \multicolumn{2}{|c|}{34 weeks } & $n=11$ & $n=10$ & \\
\hline At termination & Mean \pm SD & $150.66 \pm 67.78$ & $131.74 \pm 53.26$ & 0.606 \\
\hline \multicolumn{2}{|c|}{$P$-value $e^{2}$} & $<0.001$ & $<0.001$ & \\
\hline
\end{tabular}

Data are presented as mean $\pm S D$.

P-value1: Mann-Whitney test was used. P-value 2: Wilcoxon signed rank test was used.

Figure 2 shows the Kaplan-Meier survival analysis for patients from randomization until termination of pregnancy. Although the number of days of treatment for the esomeprazole group was slightly longer than the placebo group $(11.4 \pm 9.4$ vs. $10.3 \pm 6.3$ days), this difference was not statistically significant $(P=0.515)$. 


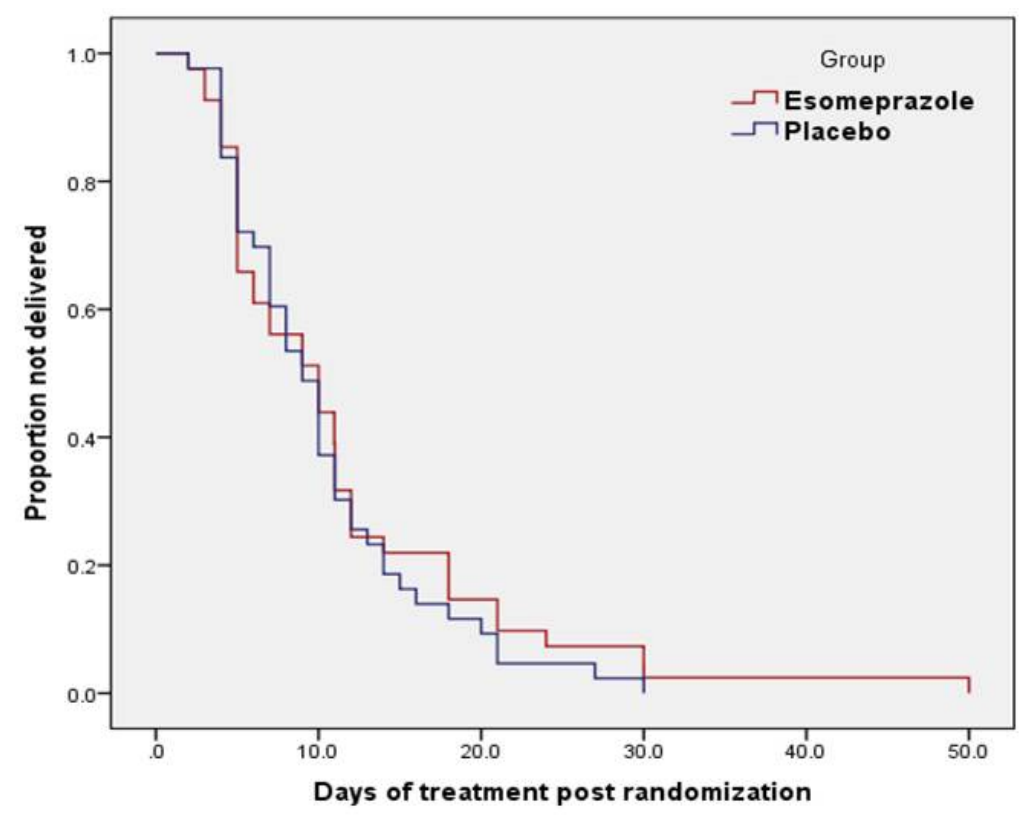

Figure 2. Survival curve for days of treatment of the study groups

Table 4. Maternal and fetal complications in the study groups

\begin{tabular}{|c|c|c|c|}
\hline Complications & $\begin{array}{l}\text { Esomeprazole group } \\
\qquad(\mathrm{n}=41)\end{array}$ & $\begin{array}{l}\text { Placebo group } \\
(\mathrm{n}=43)\end{array}$ & P-value ${ }^{1}$ \\
\hline Eclampsia & 0 & 0 & ---- \\
\hline Pulmonary edema & $1(2.4 \%)$ & 0 & 0.303 \\
\hline Cerebrovascular stroke & 0 & 0 & ---- \\
\hline DIC & 0 & 0 & ---- \\
\hline Placental abruption & $1(2.4 \%)$ & 0 & 0.303 \\
\hline ICU admission & $5(12.2 \%)$ & $3(7.0 \%)$ & 0.291 \\
\hline Number of days in ICU & $4.4 \pm 1.3$ & $4.0 \pm 0.82$ & 0.564 \\
\hline Stillbirth & $3(7.3 \%)$ & $2(4.7 \%)$ & 0.606 \\
\hline IUGR & $2(4.9 \%)$ & $4(9.3 \%)$ & 0.431 \\
\hline
\end{tabular}

DIC, disseminated intravascular coagulopathy; ICU, intensive care unit; IUGR, intrauterine growth restriction

Data are presented as $n(\%)$, \# Data are presented as mean $\pm S D$.

$P$-value ${ }^{1}$ : Chi-square test or Student's T-test were used.

Table 4 shows no statistically significant

difference in the rate of maternal and 
fetal complications between groups. No side effects of the study medications were reported.

Table 5 shows the indications of termination of pregnancy in each group. There were no statistically significant differences between groups regarding any indication. Thirteen patients in the esomeprazole group (31.7\%) versus 12 patients in the placebo group (27.9\%) continued their pregnancies through the age of fetal maturity ( $\geq 37$ weeks) $(P=0.703)$. Ultimately, 32 patients in the esomeprazole group $(78 \%)$ versus 31 patients in the placebo group $(72.1 \%)$ were delivered by cesarean section.

\section{TABLE 5: Indications of pregnancy termination in the study groups}

\begin{tabular}{lccc}
\hline Indications $\#$ & $\begin{array}{c}\text { Esomeprazole } \\
\text { group } \\
(\mathbf{n = 4 1 )}\end{array}$ & $\begin{array}{c}\text { Placebo group } \\
(\mathbf{n}=\mathbf{4 3})\end{array}$ & P-value \\
\hline Reaching the age of maturity (37 weeks gestation) & $11(25.6 \%)$ & $10(23.3 \%)$ & 0.899 \\
Uncontrolled hypertension & $12(29.3 \%)$ & $11(25.6 \%)$ & 0.705 \\
Other features of severity of preeclampsia & $7(17.1 \%)$ & $5(11.6 \%)$ & 0.476 \\
Intrauterine fetal death & $3(7.3 \%)$ & $2(4.7 \%)$ & 0.606 \\
Non-reassuring cardiotocography & $13(31.7 \%)$ & $17(39.5 \%)$ & 0.454
\end{tabular}

Data are presented as $n$ (\%), Chi-square test was used

"Summation of numbers in each indication doesn't correspond with the total number of patients as there was overlapping of indications in some cases.

\section{Discussion}

Overall, findings for this study were unable to show that esomeprazole could provide an effective treatment for preeclampsia. It revealed that esomeprazole $40 \mathrm{mg}$ daily did not effectively lower the circulating levels of antiangiogenic markers in women diagnosed with early onset preeclampsia. Furthermore, esomeprazole did not prolong the duration of pregnancy and had no effect on decreasing maternal or fetal complications.

Preeclampsia is a serious lifethreatening condition for both the mother and fetus and is associated with severe cases of maternal and perinatal morbidity. ${ }^{12}$ If a treatment were to be discovered, it would significantly impact both maternal and perinatal health. Ideal treatment should improve control of the biological disease process of preeclampsia in the placenta, reduce the risk of serious maternal and fetal complications and prolong pregnancies complicated by preeclampsia. However, there is currently no effective treatment available other than delivery of the fetus and placenta.

Previous studies have shown that the preeclamptic placenta releases antiangiogenic sFIt-1 and sEng into the maternal circulation, causing widespread maternal endothelial dysfunction and organ injury.13,14 Preeclampsia is also associated with 
oxidative stress. ${ }^{15} \mathrm{~A}$ drug that can decrease production of sFlt-1 and sEng, and reduce endothelial dysfunction and oxidative stress could provide a potential treatment for preeclampsia. ${ }^{16}$

Esomeprazole, a PPI widely used in pregnancy to treat gastric reflux, has shown promise as a potential candidate therapeutic in preclinical studies. $^{8}$ Esomeprazole is classified by the FDA as a category $\mathrm{C}$ drug in pregnancy. Large population-based cohorts and systematic reviews (including those that follow administration of esomeprazole in the first trimester) have not found any adverse effects to either mother or fetus during pregnancy. Specifically, these studies have not shown any increased risk for congenital abnormalities, spontaneous miscarriage, or preterm delivery. ${ }^{17-19}$ Thus, esomeprazole is likely to be safe in pregnancy. In this study we further reduced the chance of such risks by using the drug for a relatively short period in the late second and early third trimesters, well past the time of organogenesis.

In 2017, it was first reported that esomeprazole might have potential as a treatment for preeclampsia. $^{8}$ In laboratory studies, esomeprazole has been shown to decrease the production of sFlt-1 and sEng and their subsequent potential release from trophoblast and endothelial cells. It also has been shown to dilate whole blood vessels, decrease endothelial dysfunction and decrease blood pressure in a transgenic mouse model of preeclampsia. ${ }^{8}$ Furthermore, a prospective cohort study of 430 women supported these findings, when it was found that sFLT-1 and sEng levels were lower among women with confirmed or suspected preeclampsia who were coincidentally taking PPIs than they were for those who were not PPI users. ${ }^{20}$ However, only a single published RCT has investigated the potential use of esomeprazole in the treatment of early-onset preeclampsia. ${ }^{10}$

Regarding our primary outcome, we found that serum sFlt1 and sEng concentrations were comparable between the study groups. Concentrations of both rapidly declined after delivery, as expected, with no difference also between the groups. Therefore, the significant decrease in the level of markers is mainly attributed to the termination of pregnancy, not to the effect of esomeprazole use. Our results agreed with Cluver et al., 2018, in which no differences were found on serial measurement of both markers throughout pregnancy. ${ }^{10}$

Cluver et al., 2018, reported in their study that the median time from randomization to delivery was 11.4 days (mean, 12.9 days) in the esomeprazole group vs 8.3 days (mean, 13.1 days) in the placebo group with no significant difference in median prolongation between treatment groups (median difference, $3.0 ; 95 \% \mathrm{Cl}, 2.9$ to 8.8 ; $\mathrm{P}=0.31$ ). Our results coincide with their study as we found the mean prolongation time for the esomeprazole group was slightly longer than the placebo group (11.4 \pm 9.4 vs. $10.3 \pm 6.3)$; however, this difference was statistically not significant $(p=0.526) .{ }^{10}$ Cluver et al., 2018, reported no significant differences between treatment groups for any maternal, fetal or neonatal composite or individual outcomes, except for placental abruption $(p=0.03) .{ }^{10}$ Similarly, 
there was no statistically significant difference in the frequency of maternal or fetal complications between our study groups. In addition, there were no placental abruptions (0/43) in the placebo group and only one case $(2.4 \%)$ in the esomeprazole group. As shown in previous studies, esomeprazole has a high safety profile, ${ }^{20}$ which coincides with our findings, as none of our participants reported any side effects.

The strengths of our study include that it was a double-blinded randomized controlled trial in which neither the participants nor the clinicians were aware of the group allocations. Additionally, we recruited our calculated sample size to achieve sufficient power to detect a statistically significant difference in our primary outcome. Finally, the research point is relatively novel, with few published reports on this topic.

However, our study is not without limitations. We were not able to measure any placental tissue biomarkers due to the limited resources. Additionally, we did not measure sFlt-1 and sEng serially throughout pregnancy and immediately before delivery due to technical and financial difficulties. Lastly, the relatively small sample size is not adequately powered to detect the differences in the rate of maternal or fetal complications.

\section{Conclusion}

The findings of this research suggest that esomeprazole is not an effective drug for reducing the level of angiogenic markers or the incidence of maternal and fetal complications in patients with early-onset preeclampsia. Additionally, esomeprazole has no effect on the prolongation of the duration of pregnancy. Our findings suggest that the use of esomeprazole as a treatment for preeclampsia might warrant further investigation but that it should not yet be used for the prevention of complications or prolongation of pregnancy in cases with early-onset preeclampsia. Furthermore, the use of esomeprazole for preeclampsia should be reconsidered in studies that have sufficient power to determine if it can lead to appreciable differences in maternal and fetal outcomes. Additionally, studies for evaluation of higher doses of esomeprazole in patients with early-onset preeclampsia are recommended.

Acknowledgments The authors acknowledge the institutional research Grant obtained from the Faculty of Medicine's Grant office.

\section{References}

1. Laganà $A S$, Favilli $A$, Triolo $O$, Granese $\mathrm{R}$, Gerli $\mathrm{S}$. Early serum markers of preeclampsia: are we stepping forward? J Matern Fetal Neonatal Med. 2016 Sep;29(18):3019-23.

https://doi.org/10.3109/14767058.2015. 1113522 Epub 2015 Nov 23. PMID: 26512423.

2. Say L, Chou D, Gemmill A, Tunçalp Ö, Moller AB, Daniels J, Gülmezoglu AM, Temmerman M, Alkema L. Global causes of maternal death: a WHO systematic analysis. Lancet Glob Health. 2014 Jun;2(6):e323-33. https://doi.org/10.1016/S2214109X(14)70227-X Epub 2014 May 5. PMID: 25103301. 
3. Mayrink J, Souza RT, Feitosa FE, Rocha Filho EA, Leite DF, Vettorazzi J, Calderon IM, Sousa MH, Costa ML, Baker PN, Cecatti JG; Preterm SAMBA study group. Incidence and risk factors for Preeclampsia in a cohort of healthy nulliparous pregnant women: a nested case-control study. Sci Rep. 2019 Jul 2;9(1):9517.

https://doi.org/10.1038/s41598-01946011-3 PMID: 31266984; PMCID: PMC6606578.

4. Gestational Hypertension and Preeclampsia: ACOG Practice Bulletin, Number 222. Obstet Gynecol. 2020 Jun;135(6):e237-e260.

https://doi.org/10.1097/AOG.000000000 0003891 PMID: 32443079.

5. Webster K, Fishburn S, Maresh M, Findlay SC, Chappell LC; Guideline Committee. Diagnosis and management of hypertension in pregnancy: summary of updated NICE guidance. BMJ. 2019 Sep https://doi.org/10.1136/bmj.I5119 PMID:31501137.

6. Burton GJ, Redman CW, Roberts JM, Moffett A. Pre-eclampsia: pathophysiology and clinical implications. BMJ. 2019 Jul 15;366:I2381.

https://doi.org/10.1136/bmj.I2381 PMID: 31307997.

7. Li CM, Zhernakova A, Engstrand L, Wijmenga C, Brusselaers N. Systematic review with meta-analysis: the risks of proton pump inhibitors during pregnancy. Aliment Pharmacol Ther. $2020 \quad$ Feb;51(4):410-420. https://doi.org/10.1111/apt.15610 Epub 2020 Jan 7. PMID: 31909512.
8. Onda K, Tong S, Beard S, Binder N, Muto M, Senadheera SN, Parry L, Dilworth $M$, Renshall L, Brownfoot $F$, Hastie R, Tuohey L, Palmer K, Hirano T, Ikawa M, Kaitu'u-Lino T, Hannan NJ. Proton Pump Inhibitors Decrease Soluble fms-Like Tyrosine Kinase-1 and Soluble Endoglin Secretion, Decrease Hypertension, and Rescue Endothelial Dysfunction. Hypertension. 2017 Mar;69(3):457-468.

https://doi.org/10.1161/HYPERTENSIO NAHA.116.08408 Epub 2017 Jan 23. Erratum in: Hypertension. 2018 Apr;71(4):e11. PMID: 28115513.

9. Cluver CA, Walker SP, Mol BW, Theron GB, Hall DR, Hiscock R, Hannan N, Tong S. Double blind, randomised, placebo-controlled trial to evaluate the efficacy of esomeprazole to treat early onset pre-eclampsia (PIE Trial): a study protocol. BMJ Open. 2015 Oct 28;5(10):e008211.

https://doi.org/10.1136/bmjopen-2015008211 PMID: 26510725; PMCID: PMC4636658.

10. Cluver CA, Hannan NJ, van Papendorp E, Hiscock R, Beard S, Mol BW, Theron GB, Hall DR, Decloedt EH, Stander M, Adams KT, Rensburg M, Schubert $P$, Walker SP, Tong S. Esomeprazole to treat women with preterm preeclampsia: a randomized placebo controlled trial. Am J Obstet Gynecol. 2018 Oct;219(4):388.e1-388.e17.

https://doi.org/10.1016/j.ajog.2018.07.01 9 Epub 2018 Jul 26. PMID: 30055127.

11. Hypertension in pregnancy. Report of the American College of Obstetricians and Gynecologists' Task Force on Hypertension in Pregnancy. Obstet Gynecol. 2013 Nov;122(5):1122-1131. https://doi.org/10.1097/01.AOG.000043 7382.03963.88 PMID: 24150027. 
12. Shah S. Hypertensive disorders in pregnancy. In Sachdeva M, Miller I, editors. Obstetric and gynecologic nephrology: women's health issues in the patient with kidney disease. Cham, Switzerland: Springer Nature Switzerland; 2020. P. 11-23. https://doi.org/10.1007/978-3-03025324-0 2

13. Hoeller A, Ehrlich L, Golic M, Herse F, Perschel FH, Siwetz M, Henrich W, Dechend R, Huppertz B, Verlohren S. Placental expression of sFIt-1 and PIGF in early preeclampsia vs. early IUGR vs. age-matched healthy pregnancies. Hypertens Pregnancy. 2017 May;36(2):151-160.

https://doi.org/10.1080/10641955.2016. 1273363 Epub 2017 Feb 10. PMID: 28609172.

14. Abbas AM, Fikry EM, Mostafa TS, Shaltout AS, El-Baz MAH. Prognostic value of serum soluble FMS-like tyrosine kinase (sFlt-1) levels in preeclampsia and eclampsia; a prospective cohort study. Hypertens Pregnancy. 2018 Aug;37(3):137-143. https://doi.org/10.1080/10641955.2018. 1494188. Epub 2018 Jul 22. PMID: 30032672.

15. Silva DM, Marreiro Ddo N, Moita Neto JM, Brito JA, Neta EA, Matias JP, Sampaio FA, Nogueira Ndo N. Oxidative stress and immunological alteration in women with preeclampsia. Hypertens Pregnancy. 2013 Aug;32(3):304-11. https://doi.org/10.3109/10641955.2013. 806540 PMID: 23905609.

16. Powe CE, Levine RJ, Karumanchi SA. Preeclampsia, a disease of the maternal endothelium: the role of antiangiogenic factors and implications for later cardiovascular disease. Circulation. 2011 Jun 21;123(24):2856-69. https://doi.org/10.1161/CIRCULATIONA HA.109.853127. PMID: 21690502; PMCID: PMC3148781.
17. Gill SK, O'Brien L, Einarson TR, Koren G. The safety of proton pump inhibitors (PPIs) in pregnancy: a meta-analysis. Am J Gastroenterol. 2009 Jun;104(6):1541-5; quiz 1540, 1546. https://doi.org/10.1038/ajg.2009.122 Epub 2009 Apr 28. PMID: 19491869.

18. Hastie R, Bergman L, Cluver CA, Wikman A, Hannan NJ, Walker SP, Wikström AK, Tong S, Hesselman S. Proton Pump Inhibitors and Preeclampsia Risk Among 157720 Women. Hypertension. 2019 May;73(5):1097-1103.

https://doi.org/10.1161/HYPERTENSIO NAHA.118.12547 PMID: 30827143.

19. Saito J, Yakuwa N, Sandaiji N, Kawasaki H, Kaneko K, Suzuki T, Yamatani A, Sago H, Murashima A. Esomeprazole During Pregnancy and Lactation: Esomeprazole Levels in Maternal Serum, Cord Blood, Breast Milk, and the Infant's Serum. Breastfeed Med. $2020 \quad$ Sep;15(9):598-601. https://doi.org/10.1089/bfm.2020.0175 Epub 2020 Jul 7. PMID: 32635742.

20. Saleh L, Samantar R, Garrelds IM, van den Meiracker AH, Visser W, Danser AHJ. Low Soluble Fms-Like Tyrosine Kinase-1, Endoglin, and Endothelin-1 Levels in Women With Confirmed or Suspected Preeclampsia Using Proton Pump Inhibitors. Hypertension. 2017 Sep;70(3):594-600. https://doi.org/10.1161/HYPERTENSIO NAHA.117.09741 Epub 2017 Jul 17. PMID: 28716993. 